\title{
A Symposium on Academic Freedom and Collegial Governance in Sweden and Canada
}

\author{
Howard Woodhouse ${ }^{1}$
}

Published online: 11 May 2019

(c) Springer Nature B.V. 2019

The three articles in this international symposium were originally presented at the European Conference for Educational Research of the European Education Research Association at University College, Copenhagen, in August 2017. Each article addresses the important theme of academic freedom and collegial governance. However, they do so in different ways and it is the contrasts between them as well as their commonalities that may strike the reader as suggestive of questions that evoke further consideration.

Academic freedom as a distinctive kind of freedom enables the advancement and dissemination of shared understanding on the basis of evidence brought forward in support of any knowledge claim. Collegial governance in the form of university faculty making decisions about academic matters can support such freedom and ensure that those engaged in the key functions of teaching and research determine the goal of education as the advancement of knowledge.

In his article, "Public Health is Politics," Jan Sundin examines the historical trajectory of public health policy in Sweden and the tensions surrounding it since its inception during the Enlightenment. Professor Sundin's thesis is that public health policy is determined as much by politics as it is by the scientific research supporting it, and a recent paradigm shift is a case in point. An emphasis on social structural factors as determinants of health, like the level of citizens' participation in society, has been eclipsed by individual factors such as freedom of choice. The change resulted from government policy influenced by an opposition with an agenda of privatizing health care and the reorganization of the Public Health Institute, where interdisciplinary research had been the norm. Although the result was greater cooperation with universities, funding for social science research was cut, medically oriented epidemiology became the dominant form of inquiry with the lion's share of monies, and the institute itself became an extended arm of government. While alternative kinds of interdisciplinary research were not censored, their stature as well as their funding was severely reduced. As a result, academic freedom

Howard Woodhouse

hrw652@mail.usask.ca

1 University of Saskatchewan, Saskatoon, Canada 
has been curtailed by government policy that largely ignores the value of knowledge that increases understanding of the relationship between health and society. And this illustrates just how fragile this kind of research has become in the current political climate where it is seen as somehow less worthy than supposed hard science.

Ian Winchester's article, "Academic Freedom and Collegial Governance in the Context of an Increasingly Commercialized University," examines the history of collegial governance in Western universities since the Middle Ages to the present day and poses questions about the ways in which academic freedom may be threatened in a commercialized university. In the modern era, universities in Canada and elsewhere became dependent upon funding from the state, and as this supply dwindled they turned to the corporate sector to fill the vacuum. At times this has resulted in a threat to research critical of the products of the pharmaceutical industry ${ }^{1}$. Professor Winchester's main interest is in the extent to which increasing commercialization may undermine collegial governance in the form of decision making power by elected faculty and students in the academic Senate. He shows that the process of commercialization occurs in several ways, including scholarly publishing where the cost of journals and books restricts access both to individuals and university libraries. Private donations to professional faculties at his own university have no strings attached and have had little impact on collegial governance even though faculty and students cannot vote on their acceptance in Senate or elsewhere. In general, Professor Winchester is hopeful that universities can steer a course between government funding and commercialization analogous to that of their mediaeval counterparts who benefited from tensions between the monarch and the Church.

Howard Woodhouse's article, "Academic Freedom and Collegial Governance Under Threat at a Canadian University," is a case study of his own university, where administrative fiat in the form of a presidential veto over tenure has been used. Even though the veto has been rescinded, it has been one of the internal forces threatening collegial governance and academic freedom. Since academic freedom is indispensable to the critical search for knowledge at the core of university life, and collegial decision making in the hands of faculty is capable of supporting it, their importance cannot be overestimated. The growth of the corporate model of universities since the 1980s has undermined these twin concepts by changing the ways in which universities have been funded and how senior administrators regard their function. Nevertheless, Professor Woodhouse shows how resistance to this model by faculty and students at his own university could appeal to its own long standing traditions and show that a restructuring process was unnecessary and alien to its distinctive culture. Despite such success, new forms of external corporate influence have since taken root that continue to pose a threat to academic freedom and collegial governance.

In conclusion, all three authors agree that cuts in government funding have an effect on the academic freedom of researchers, particularly in the humanities and social sciences. This trend holds true of a health research institute in Sweden, where government policy now determines its operations, and universities in Canada that still enjoy a relative autonomy. The extent to which collegial governance can support

\footnotetext{
1 See, for example, Jon Thompson, Patricia Baird, \& Jocelyn Downie, The Olivieri Report: The Complete Text of the Report of the Independent Inquiry Commissioned by the Canadian Association of University Teachers, (Toronto: James Lorimer 2001).
} 
academic freedom depends on the ability of faculty to ensure that decision making remains in their hands as key members of the collegium. And this, in turn, begs the question of whether or not senior administrators have either the scope or the will to change the course set by governments engaged in defunding universities and research institutes.

Publisher's Note Springer Nature remains neutral with regard to jurisdictional claims in published maps and institutional affiliations. 